\title{
QSPR ANALYSIS OF CERTAIN DEGREE AND ECCENTRICITY BASED TOPOLOGICAL INDICES AND BUTANE DERIVATIVES
}

\author{
Anjusha Asok ${ }^{1}$ and Joseph Varghese Kureethara, ${ }^{2, *}$ \\ ${ }^{1}$ Department of Mathematics, CHRIST (Deemed to be University), \\ Bangalore-560029, (Karnataka) India \\ ${ }^{2}$ Department of Mathematics, CHRIST (Deemed to be University), \\ Bangalore-560029, (Karnataka) India \\ *E-mail : frjoseph@christuniversity.in
}

\begin{abstract}
Butane derivatives are chemical compounds formally derived from Butane $\mathrm{C}_{4} \mathrm{H}_{10}$ by replacement of one or more hydrogen atoms with other atoms or functional groups. In this paper, we do the QSPR analysis of few Butane derivatives with respect to some selected degree based topological indices and one eccentricity based topological index. In QSPR studies, topological indices are extensively used in determining specific bioactivity of chemical compounds. Our study showcases some important results on the correlation between Heavy atomic count, Complexity, Density, Surface tension and Index of refraction of Butane derivatives with the selected topological indices which further helps in characterizing the predicting power of these topological indices.
\end{abstract}

Keywords: QSPR, Molecular graph, Topological Index, Butane Derivatives, Zagreb index

(c) RASĀYAN. All rights reserved

\section{INTRODUCTION}

Mathematical Chemistry is the area of research engaged in highlighting and applying the theoretical framework of Mathematics to Chemistry. It concerns itself principally with the mathematical modeling of chemical phenomena. One of the very interesting fields of Mathematics which has a wide range of applications in Chemistry is Graph Theory which further resulted in so-called Chemical Graph Theory.

The molecular graph is the topological representation of a molecule. It is obtained by treating each atom and bond between atoms of a compound as vertex and edge of the graph, respectively. Hence in the topological representation $\mathrm{H}_{2} \mathrm{~S}$ (Hydrogen Sulphide) and $\mathrm{H}_{2} \mathrm{O}$ (Water), $\mathrm{NaCl}$ (Sodium Chloride) and $\mathrm{HCl}\left(\right.$ Hydrogen Chloride), $\mathrm{C}_{4} \mathrm{H}_{9} \mathrm{Cl}(1$-Chlorobutane) $)$ and $\mathrm{C}_{4} \mathrm{H}_{9} \mathrm{Br}(1$-Bromobutane) etc. have the same molecular graphs. Conventionally, in a molecular graph, we consider the only hydrogen suppressed molecule and every different type of bonds are represented by a single edge. ${ }^{1-4}$

QSARs(Quantitative structure-property relationship)/QSPRs(Quantitative structure-activity relationship) have become powerful tools in contemporary chemical and medicinal research, as they have made it possible to predict the biochemical activities. ${ }^{5-8}$ Once a correlation between structure and biological activity or a physiochemical property is established, it is possible to predict the activity/property of any number of structurally related compounds. In a recent study, it is found out that Heavy atomic count, Hydrogen bond acceptor count, Complexity and Surface tension of Butane derivatives have a close correlation with the Redefined first Zagreb index, the Sum connectivity index, the Redefined third Zagreb index and the Reformulated first Zagreb index, respectively. ${ }^{9}$

\section{EXPERIMENTAL}

\section{Material and Methods}

We have used here seven degree-based and one eccentricity based topological indices. They are: Redefined third Zagreb index $\left(\operatorname{ReZG}_{3}(\mathrm{G})\right)^{10}$, Reformulated second Zagreb index $\left(\operatorname{EM}_{2}(\mathrm{G})\right)^{11-18}$, modified Rasayan J. Chem., 12(2), 464-470(2019)

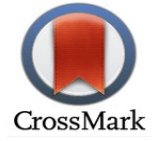


Reformulated second Zagreb index $\left({ }^{\mathrm{m}} \mathrm{EM}_{2}(\mathrm{G})\right)^{16}$, first, second and third Zagreb coindices $\left(\bar{M}_{1}(\mathrm{G}), \bar{M}_{2}(\mathrm{G})\right.$, $\left.\bar{M}_{3}(\mathrm{G})\right)^{11,19-29}$, second Zagreb eccentricity index $\left(\mathrm{E}_{2}(\mathrm{G})\right)^{30-36}$ and Hyper Zagreb index $(\mathrm{HM}(\mathrm{G}))^{12,20,27,37-48}$ for modeling five representative physiochemical properties such as Heavy atomic count, Complexity, Density, Surface tension, Index of refraction of the fourteen Butane derivatives. As the molecular graphs of isomorphic graphs are the same, we considered here only nonisomorphic Butane derivatives. For example, $\mathrm{C}_{4} \mathrm{H}_{9} \mathrm{Cl}$ will not find plaace among the fourteen Butane derivatives as it is isomorphic to $\mathrm{C}_{4} \mathrm{H}_{10}$. The values of the topological indices for fourteen Butane derivatives are enumerated manually and listed in the tables 1 and 2. The modeling is done by computing the Pearson correlation coefficient between each of these topological indices with the five selected physiochemical properties of Butane derivatives using Origin which is given by tables 4 and 5. The experimental values for the physiochemical properties of fourteen Butane derivatives are listed in Table-3. The values of phythesiochemical properties of Butane derivatives are taken from PubChem. ${ }^{49}$

\section{Topological Indices}

We give a brief account of the topological indices used in this paper. ${ }^{20,50}$ The Reformulated Second Zagreb Index ${ }^{16}$ was coined in 2004. Most of the papers on the Reformulated second Zagreb index either have a discussion on a various properties ${ }^{18,51}$ or deal with the computation of the index of various networks and compounds. $^{15,18,51,52}$ There is no evidence of QSPR studies until now.

In 2008, the first and second Zagreb coindices were defined. It is very evident from the studies in that majority of the articles are on the structural enumeration of different classes of graphs namely Hamiltonian graphs, Composite graphs etc. and the number of studies on the structure-property relationship with the first and second Zagreb coindices is almost zero. ${ }^{11,22-24,27}$

The third Zagreb coindex is relatively new. ${ }^{29}$ Not many works are available in the literature about it since 2016. In this paper, we see that the predicting power of the third Zagreb coindex is very high which is definitely an important result contributing to the chemical world of QSPR studies.

The second Zagreb eccentricity index was introduced in 2010. ${ }^{11,35}$ Later, in 2013, the Redefined third Zagreb index ${ }^{53}$ and the Hyper Zagreb index ${ }^{47}$ started appearing in the literature.

Most of the articles incorporating with the Redefined third Zagreb index focus on the computation of this index of numerous structurally important chemical compounds such as Graphene and various nanostructures. ${ }^{2,10,42}$

Most of the works conducted on Redefined third Zagreb index give properties and bounds for the index ${ }^{10,18,52,54,55}$ and even comparisons are done with many other topological indices. ${ }^{30,31,35}$ Similar to all other topological indices, many properties and bounds on the Hyper Zagreb index are also computed ${ }^{27,32,48}$ but researchers found to have more interest in investigating the chemical constitution of compounds with Hyper Zagreb index. ${ }^{37,38,40-43,46,56,57}$ It is found that no studies are conducted on the correlation between the physiochemical properties of compounds with the molecular descriptors for all the three indices.

\section{Definitions}

We now see the definitions of some of these Zagreb indices. ${ }^{58,59}$ Let $d(u)$ be the degree of the vertex $u$ of a graph G. Then we have the following indices.

The Redefined third Zagreb index $\quad: \operatorname{ReZG}_{3}(\mathrm{G})=\sum(\mathrm{d}(\mathrm{u}) \mathrm{d}(\mathrm{v}))(\mathrm{d}(\mathrm{u})+\mathrm{d}(\mathrm{v}))$, for all edges $u v$ of the graph G.

Let $\mathrm{u}, \mathrm{v}$ be non-adjacent in graph $\mathrm{G}$.

The first Zagreb coindex

The second Zagreb coindex

The third Zagreb coindex

Hyper Zagreb index

Reformulated second Zagreb index

graph G.

Modified Reformulated Zagreb index: ${ }^{\mathrm{m}} \mathrm{EM}_{2}(\mathrm{G})=\sum 1 /(\mathrm{d}(\mathrm{e}) \mathrm{d}(\mathrm{f}))$, for all adjacent edges $e$ and $v$ of the graph G.

The second Zagreb eccentricity index: $\mathrm{E}_{2}(\mathrm{G})=\sum(\mathrm{e}(\mathrm{u}) \mathrm{e}(\mathrm{v}))$, for all edges $u v$ of the graph $\mathrm{G}$ 
RASĀYAN J. Chem.

Vol. 12 | No. 2 |464 - 470| April - June | 2019

\section{Comparison of Parameters and Indices}

Table-1: Compounds and Indices

\begin{tabular}{c|c|c|c|c}
\hline Name of the Compound & $\mathrm{ReZG}_{3}(\mathrm{G})$ & $\mathrm{EM}_{2}(\mathrm{G})$ & ${ }^{\mathrm{m}} \mathrm{EM}_{2}(\mathrm{G})$ & $\bar{M}_{1}(G)$ \\
\hline 1,4-butanedithiol & 60 & 12 & 1.5 & 31 \\
\hline 2-butanone & 60 & 14 & 1.25 & 16 \\
\hline 1,3-butanediol & 76 & 18 & 1.0833 & 31 \\
\hline butane dinitrile & 76 & 12 & 1.5 & 31 \\
\hline butanediamide & 124 & 50 & 1.5 & 68 \\
\hline butane-1-sulfoamide & 146 & 66 & 1.5833 & 66 \\
\hline 1-butanethiol & 44 & 8 & 1.25 & 18 \\
\hline 1,4-diaminobutane & 60 & 12 & 1.5 & 31 \\
\hline butane-1,4-disulfonic acid & 216 & 119 & 2.055 & 188 \\
\hline butyraldehyde & 44 & 8 & 1.25 & 18 \\
\hline 2,3-butanedione & 92 & 24 & 1.5 & 25 \\
\hline butanedihydrazide & 154 & 60 & 1.888 & 112 \\
\hline 1-butanesulfonyl chloride & 60 & 66 & 1.5833 & 66 \\
\hline butyl-2-benzene & 152 & 63 & 1.875 & 124 \\
\hline
\end{tabular}

Table-2: Compounds and Indices

\begin{tabular}{c|c|c|c|c}
\hline Name of the Compound & $\overline{M_{2}}(G)$ & $\overline{M_{3}}(G)$ & $\mathrm{E}_{2}(\mathrm{G})$ & $\mathrm{HM}(\mathrm{G})$ \\
\hline 1,4-butanedithiol & 67 & 6 & 73 & 50 \\
\hline 2-butanone & 10 & 4 & 22 & 66 \\
\hline 1,3-butanediol & 25 & 7 & 40 & 82 \\
\hline butane dinitrile & 67 & 6 & 73 & 50 \\
\hline butanediamide & 55 & 18 & 113 & 130 \\
\hline butane-1-sulfoamide & 52 & 18 & 113 & 152 \\
\hline 1-butanethiol & 13 & 4 & 36 & 50 \\
\hline 1,4-diaminobutane & 67 & 6 & 73 & 50 \\
\hline butane-1,4-disulfonic acid & 162 & 52 & 368 & 270 \\
\hline butyraldehyde & 13 & 4 & 36 & 50 \\
\hline 2,3-butanedione & 16 & 7 & 24 & 100 \\
\hline butanedihydrazide & 114 & 40 & 260 & 173 \\
\hline 1-butanesulfonyl chloride & 52 & 18 & 113 & 152 \\
\hline butyl-2-benzene & 109 & 14 & 214 & 146 \\
\hline
\end{tabular}

Table-3: Compounds and Physiochemical Properties

\begin{tabular}{c|c|c|c|c|c}
\hline Name of the Compound & Heavy Atomic Count & Complexity & Density & Surface Tension & Index of Refraction \\
\hline 1,4-butanedithiol & 6 & 17.5 & 1.03 & 31.1 & 1.51 \\
\hline 2-butanone & 5 & 38.5 & 8.32 & 22.9 & 1.37 \\
\hline 1,3-butanediol & 6 & 28.7 & 9.96 & 34.9 & 1.44 \\
\hline butane dinitrile & 6 & 92 & 1.01 & 40.7 & 1.42 \\
\hline butanediamide & 8 & 96.6 & 1.18 & 53 & 1.49 \\
\hline butane-1-sulfoamide & 8 & 133 & 1.15 & 41.9 & 1.47 \\
\hline 1-butanethiol & 5 & 13.1 & 8.5 & 24.8 & 1.44 \\
\hline 1,4-diaminobutane & 6 & 17.5 & 8.65 & 35.8 & 1.46 \\
\hline butane-1,4-disulfonic acid & 12 & 266 & 1.66 & 77.9 & 1.54 \\
\hline butyraldehyde & 5 & 24.8 & 8.18 & 23.1 & 1.37 \\
\hline 2,3-butanedione & 6 & 71.5 & 9.75 & 27.3 & 1.38 \\
\hline butanedihydrazide & 10 & 119 & 1.28 & 59 & 1.53 \\
\hline 1-butanesulfonyl chloride & 8 & 133 & 1.26 & 36.4 & 1.45 \\
\hline butyl-2-benzene & 10 & 80 & 8.66 & 29 & 1.49 \\
\hline
\end{tabular}


Table-4: Pearson's Correlation Coefficient

\begin{tabular}{c|c|c|c|c}
\hline & $\mathrm{ReZG}_{3}(\mathrm{G})$ & $\mathrm{EM}_{2}(\mathrm{G})$ & ${ }^{\mathrm{m}} \mathrm{EM}_{2}(\mathrm{G})$ & $\overline{M_{1}}(G)$ \\
\hline Heavy Atomic Count & 0.9238 & 0.9440 & 0.9116 & 0.9833 \\
\hline Complexity & 0.8298 & 0.9327 & 0.7733 & 0.8501 \\
\hline Density & 0.7339 & 0.8556 & -0.2745 & 0.7784 \\
\hline Surface Tension & 0.8061 & 0.7854 & 0.7064 & 0.8040 \\
\hline Index of Refraction & 0.68204 & 0.6580 & 0.7236 & 0.7530 \\
\hline
\end{tabular}

Table-5: Pearson's Correlation Coefficient

\begin{tabular}{c|c|c|c|c}
\hline & $\overline{M_{2}}(G)$ & $\overline{M_{3}}(G)$ & $\mathrm{E}_{2}(\mathrm{G})$ & $\mathrm{HM}(\mathrm{G})$ \\
\hline Heavy Atomic Count & 0.9001 & 0.9081 & 0.9637 & 0.94053 \\
\hline Complexity & 0.7305 & 0.8827 & 0.8246 & 0.92853 \\
\hline Density & 0.7120 & 0.9065 & 0.7864 & 0.8707 \\
\hline Surface Tension & 0.8024 & 0.9176 & 0.8390 & 0.8081 \\
\hline Index of Refraction & 0.8360 & 0.7254 & 0.7916 & 0.6356 \\
\hline
\end{tabular}

\section{RESULTS AND DISCUSSION}

Many observations and conclusions can be made based on the Tables obtained by evaluating the Pearson correlation coefficient of Butane derivatives using the software Origin.

Most of the topological indices found to be positively correlated with the corresponding topological indices except the correlation between modified Reformulated Zagreb index $\left({ }^{\mathrm{m}} \mathrm{EM}_{2}(\mathrm{G})\right)$ and Density $(\mathrm{r}=-$ $0.2745)$

Firstly, it is very evident from correlation tables 4 and 5 that all the topological indices of our concern are closely correlated with the physical property Heavy atomic count with a correlation coefficient varying between 0.9 and 0.98. In which the Reformulated second Zagreb index $\left(\mathrm{EM}_{2}(\mathrm{G})\right)$ and Hyper Zagreb index $(\mathrm{HM}(\mathrm{G}))$ are having a correlation coefficient approximately equal to 0.94 and a high-value correlation of 0.98 with the first Zagreb coindex $\left(\bar{M}_{1}(\mathrm{G})\right)$. Hence without any ambiguity, we can say that the first Zagreb coindex $\left(\bar{M}_{1}(\mathrm{G})\right)$ is the right one for predicting the physical property, Heavy atomic count.

The contribution of Zagreb coindices, especially the third Zagreb coindex $\left(\bar{M}_{3}(\mathrm{G})\right)$ is an inevitable factor while discussing the correlation between the physiochemical properties and topological indices. The third Zagreb coindex is having a close correlation with all the four physiochemical properties(Heavy atomic count, Complexity, Density and Surface tension) except the Index of refraction with correlation coefficient $\mathrm{r}=0.7254$. This implies that the third Zagreb coindex $\left(\bar{M}_{3}(\mathrm{G})\right)$ is a completely adequate topological index for the investigation of structure-property relationship.

The Reformulated Zagreb indices were introduced in the year 2004. Since 2004 no QSPR studies on Reformulated second Zagreb index is attracted by researchers. But we in this paper explored its role in structure-property relations and we could easily verify that Reformulated second Zagreb index $\left(\left(\operatorname{EM}_{2}(\mathrm{G})\right)\right.$ has a good correlation with Heavy atomic count $(\mathrm{r}=0.94)$ and complexity $(\mathrm{r}=0.93)$.

In this QSPR study, one thing which grabs our attention is that none of the topological indices discussed here shows a strong correlation with the property, Index of refraction.

Lastly, above all, the one main observation which agrees on the above argument, that is, all the four physiochemical properties except Index of refraction are exhibiting significant correlation with at least one among the eight descriptors.

We give the plots of each of the physiochemical property with its most correlated topological index which even more clarify the above conclusions.

Figure-1 is the plot of Heavy Atomic Count and the Second Zagreb Coindex.

Figure-2 is the plot of Complexity and the Reformulated Second Zagreb index

In the Fig.-1 and 3, we see the graphs that are representing the correlation of Heavy atomic count and the second Zagreb Coindex and Density and the third Zagreb Coindex, respectively. They may look to be not correlating. However, the appearance is because of the scale. That is, the range in which the values of the physical properties and the topological indices for plotting of Butane derivatives is large.

Finally, Fig. -4 gives the plot of the Surface tension and the third Zagreb Coindex. 
RASĀYAN J. Chem.

Vol. 12 | No. 2 |464 - 470| April - June | 2019

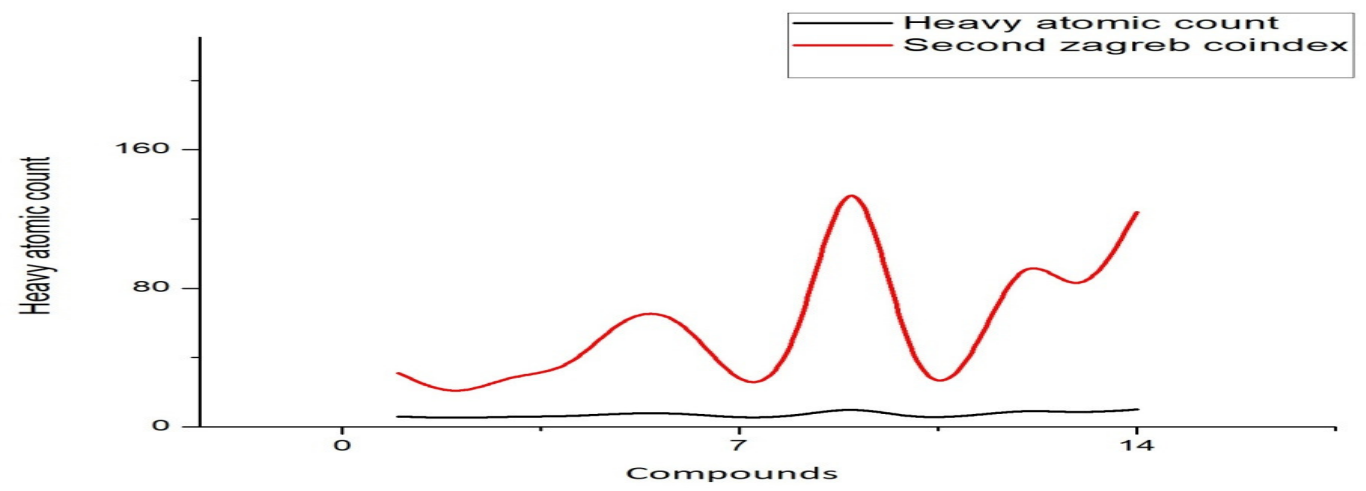

Fig.-1: Heavy Atomic Count and the Second Zagreb Coindex

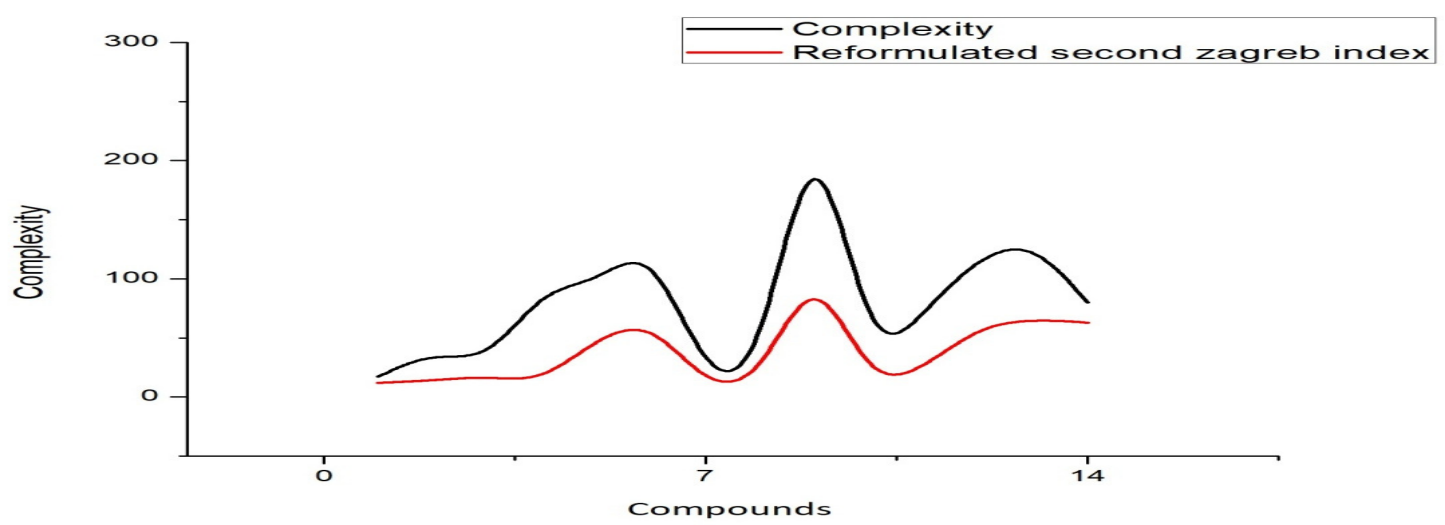

Fig.-2: Complexity and Reformulated the Second Zagreb Index

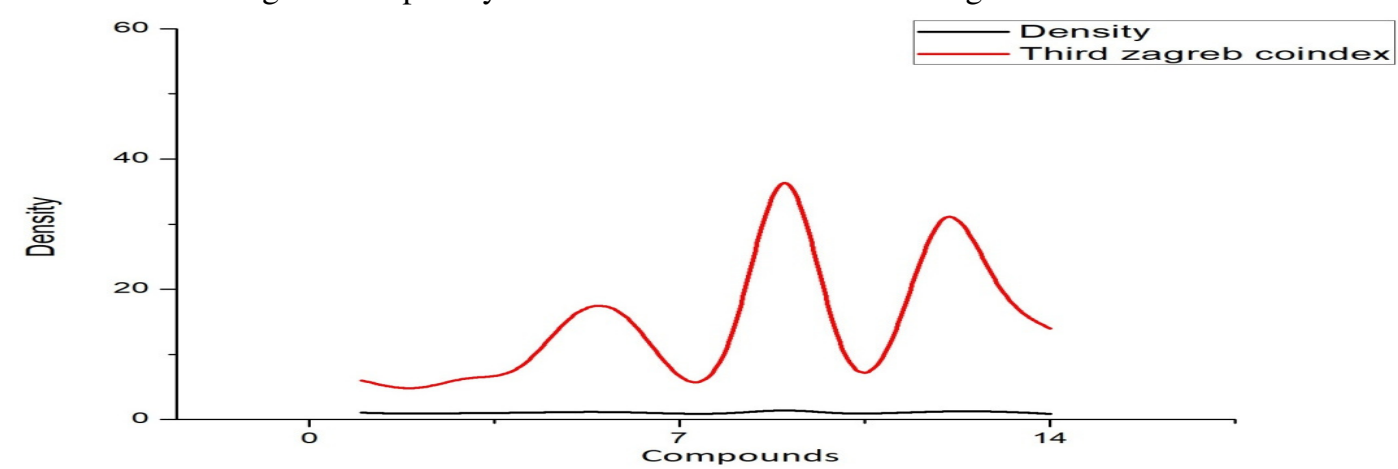

Fig.-3: Density and the Third Zagreb Coindex

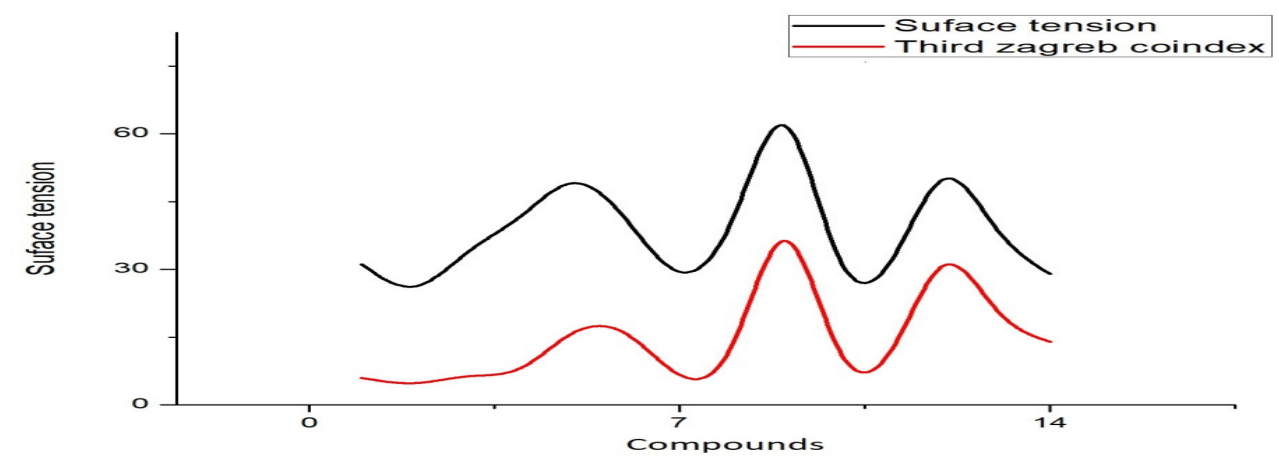

Fig.-4: Surface Tension and the Third Zagreb Coindex 
RASĀYAN J. Chem.

Vol. 12 | No. 2 |464 - 470| April - June | 2019

\section{CONCLUSION}

QSPR studies from the very beginning of its journey seized the attention of both Mathematicians as well as Chemists since it has the potential to be the cause of new inventions. Especially, finding the properties of compounds without any experimentation that is actually time-consuming.

In this paper we see that among all the topological indices of our concern, the third Zagreb coindex has a good correlation with all the four physiochemical properties say, Heavy atomic count, Complexity, Surface tension and Density. We can see that first Zagreb coindex is highly correlated with Heavy atomic count. Hence we can say that this paper on QSPR analysis is an answer for the researchers who interrogate over the importance of topological indices.

1. N. De, J. Nanosci., 2016, (2016).

\section{REFERENCES}

2. W. Gao and M. K. Siddiqui, J. Chem., 2017, (2017), DOI:10.1155/2017/6540754

3. W. Gao, W. Wang and M. R. Farahani, J. Chem., 2016, (2016), DOI:10.1155/2016/3216327

4. M. F. Nadeem, S. Zafar and Z. Zahid, Appl. Math. Comput., 273, 125, (2016), DOI: 10.1016/j.amc.2015.10.010

5. N. Akgunes, K. C. Das and A. S. Cevik, Top. Chem. Graph Theory, 16, 3, (2014), DOI: 10.1186/1029-242X-2013-44

6. A. R. Ashrafi, T. Došlic and A. Hamzeh, MATCH Commun. Math. Comput. Chem., 65, 85, (2011).

7. N. De, Int. J. Discrete Math., 2, (2017).

8. T. Doslic, Iran. J. Math. Chem., 3, 25, (2012), DOI: 10.22052/IJMC.2012.5199

9. A. Asok and J. V. Kureethara, Oriental J. Chem., 34, (2018), DOI: 10.13005/ojc/3404018

10. R. P. Kumar, D. S. Nandappa, M. R. R. Kanna and P. Bettampady, Int. J. Math. Anal., 11, 493, (2017), DOI: $10.12988 /$ ijma.2017.7454

11. K. C. Das, D.-W. Lee and A. Graovac, Ars Math. Contemp., 6, (2012), DOI: 10.26493/18553974.237.48a

12. N. De, arXiv preprint arXiv:1703.08325, (2017), DOI: 10.1007/s11464-015-0431-9.

13. A. Ilić and B. Zhou, Discrete Appl. Math., 160, 204, (2012), DOI: 10.1016/j.dam.2011.09.021

14. S. Ji, X. Li and B. Huo, MATCH Commun. Math. Comput. Chem., 72, 723, (2014).

15. V. R. Kulli, Int. J. Math. Arch., 7, (2017).

16. A. Miličević, S. Nikolić and N. Trinajstić, Molecular Diversity, 8, 393, (2004), DOI:10.1023/B:MODI.0000047504.14261.2a

17. G. Su, L. Xiong, L. Xu and B. Ma, Filomat, 25, 75, (2011), DOI: 10.2298/FIL1104075S

18. B. Zhou and N. Trinajstić, J. Math. Chem., 48, 714, (2010), DOI: 10.1007/s10910-010-9704-4

19. A. R. Ashrafi, A. Hamzeh and S. Hossein-Zadeh, J. Appl. Math. Inf., 29, 327, (2011), DOI: 10.1016/j.dam.2010.05.017.31

20. V. R. Kulli, B. Chaluvaraju and H. S. Boregowda, South Asian J. Math., 6, 263, (2016).

21. I. Gutman, B. Furtula, Z. K. Vukicevic and G. Popivoda, MATCH Commun. Math. Comput. Chem., 74, 5, (2015).

22. S. M. Hosamani, P. V. Patil and S. H. Malghan, J. Information and Optimization Sciences, 38, 417 , (2017), DOI: $10.1080 / 02522667.2015 .1123461$

23. H. Hua and S. Zhang, MATCH Commun. Math. Comput. Chem., 68, 199, (2012).

24. H. Hua, A. R. Ashrafi and L. Zhang, Filomat, 26, 1215, (2012), DOI: 10.2298/FIL1206215H

25. M. Liu, F. Li and K. C. Das, MATCH Commun. Math. Comput. Chem., 70, 939, (2013).

26. T. Mansour and C. Song, Int. J. Comb., 2012, (2011), DOI: 10.1155/2012/909285

27. K. Pattabiraman and M. Vijayaragavan, Bull. Int. Math.Virtual Inst., 7, 31, (2016).

28. M. Tavakoli, F. Rahbarnia and A. R. Ashrafi, J. Discrete Math., 2014, (2014), DOI: $10.1155 / 2014 / 292679$

29. M. Veylaki, M. J. Nikmehr and H. A. Tavallaee, J. Appl. Math. Comput., 50, 315, (2016), DOI: 10.1007/s12190-015-0872-Z

30. K. C. Das, Croat. Chem. Acta, 89, 505, (2016).

31. K. C. Das, I. Gutman and B. Horoldagvac, MATCH Commun. Math. Comput. Chem., 68, 189, (2012). 
RASĀYAN J. Chem.

Vol. 12 | No. 2 |464 - 470| April - June | 2019

32. Z. Du, B. Zhou and N. Trinajstić, Croat. Chem. Acta, 85, 359, (2012), DOI:10.5562/cca2020

33. M. K. Jamil, M. R. Farahani, M. R. R. Kanna and R. P. Kumar, J. Chem. Pharm. Res., 8, 80, (2016).

34. D. W. Lee, Adv. Appl. Math. Sci., 12, 403, (2013).

35. D. Vukičević and A. Graovac, Acta Chim. Slov., 57, 524, (2010).

36. R. Xing, B. Zhou and N. Trinajstić, Croat. Chem. Acta, 84, 493, (2011), DOI: 10.5562/cca1801

37. B. Basavanagoud and S. Patil, Iran. J. Math. Chem., 7, 89, (2016), DOI: 10.1007/s12190-015-0872Z

38. B. Basavanagoud and S. Patil, Math. Sci. Lett., 6, 1, (2017), DOI: 10.18576/msl/060212

39. B. Chaluvaraju, H. S. Boregowda and S. A. Diwakar, Int. J. Adv. Math., 4, 21, (2017).

40. F. Falahati-Nezhad and M. Azari, J. Appl. Math. Inf., 34, 319, (2016), DOI: 10.14317/jami.2016.319

41. M. R. Farahani, J. Chem. Mater. Res., 2, 16, (2015).

42. M. R. Farahani, Int. J. Eng. Technol.Res., 3, 1, (2015).

43. M. R. Farahani, Frontiers of Math. Appl., 2, 1, (2015), DOI: 10.12966/fmia.06.01.2015

44. I. Gutman, Bulletin de lAcademie Serbe des Sciences et des Arts, Classe des Sciences Techniques, (2017).

45. V. R. Kulli, B. Chaluvaraju and H. S. Boregowda, Int. J. Math. Arch., 9, (2018).

46. M. Rezaei, W. Gao, M. K. Siddiqui and M. R. Farahant, Sigma, 35, 707, (2017).

47. G. H. Shirdel, H. Rezapour and A. M. Sayadi, Iran. J. Math. Chem., 4, 213, (2013). DOI: 10.22052/IJMC.2013.5294

48. S. Wang, W. Gao, M. K. Jamil, M. R. Farahani and J.-B. Liu, arXiv preprint arXiv:1612.02361, (2016).

49. PubChem Online.. https://pubchem.ncbi.nlm.nih.gov/

50. M. N. Husin, R. Hasni and M. Imran, Int. J. Networking Virt. Organ., 17, 46, (2017), DOI:10.1504/IJNVO.2017.083543.

51. N. De, arXiv preprint arXiv:1704.05476, (2017).

52. N. De, Appl. Math. Sci., 6, 5005, (2012), DOI: 10.1007/s10910-010-9704-4

53. P. S. Ranjini, V. Lokesha and A. Usha, Int. J. Graph Theory, 1, 116, (2013).

54. V. R. Kulli, J. Comput. Math. Sci., 8, 650, (2017), DOI: $10.29055 / \mathrm{jcms} / 704$

55. K. Xu, Bounds in Chemical Graph Theory Mainstreams, University of Kragujevac, Faculty of science, Serbia, p. 189, (2017).

56. M. R. R. Kanna, R. P. Kumar and D. S. Nandappa, Int. J. Appl. Math., 30, 73, (2017), DOI: 10.12732/ijam.v30i1.6

57. W. Gao and M. R. Farahani, J. Discrete Math. Sci. Cryptography, 20, 515, (2017).

58. V. R. Kulli, Ann. Pure Appl. Math., 13, 165, (2017), DOI:10.1080/09720529.2016.1220088

59. I. Gutman, V. R. Kulli, B. Chaluvaraju and H. S. Boregowda, J. Int. Math. Virtual Inst., 7, 53, (2017), DOI: 10.7251/JIMVI170153G

60. W. Gao, M. R. R. Kanna, E. Suresh and M. R. Farahani, Int. J. Graph Theory, 1, 173, (2017).

[RJC-5093/2018] 